\title{
Bio-functionalized titanium surfaces with the modified silk fibroin carrying titanium binding motif enhanced the ossific differentiation of MC3T3-E1
}

\author{
Mai Watanabe ${ }^{1}$, Ujjal Bhawala ${ }^{2}$, Shinji Takemoto ${ }^{3}$, Norihiro Nishiyama ${ }^{2}$, Yuichi \\ Nakahara $^{4}$, Ken-ichiro Tatematsu ${ }^{4}$, Hideki Sezutsu ${ }^{4}$, Nobuo Kuwabara ${ }^{5}$, Tamiko \\ Minamisawa $^{1}$, Kiyotaka Shiba ${ }^{1}$, and Tetsuo Asakura ${ }^{6}$ \\ ${ }^{1}$ Public Interest Incorporated Foundation Japanese Foundation for Cancer Research \\ ${ }^{2}$ Nihon University School of Dentistry Graduate School of Dentistry at Matsudo \\ ${ }^{3}$ Iwate Medical University \\ ${ }^{4}$ National Agriculture and Food Research Organization \\ ${ }^{5}$ Gunma Sericultural Technology Center \\ ${ }^{6}$ Tokyo University of Agriculture and Technology
}

September 5, 2020

\begin{abstract}
Silk fibroin (SF) from Bombyx mori has superior properties as both a textile and a biomaterial, and has been used to functionalize the surfaces of various medical inorganic materials including titanium (Ti). In this paper, we endowed SF with reversible binding ability to Ti by embedding a titanium binding motif (minTBP-1, RKLPDA). Artificial SF proteins were first created by conjugating gene cassettes for SF motif (AGSGAG) and minTBP-1 motif with different ratios, which have been shown to bind reversibly to Ti surfaces in quartz crystal microbalance analyses. Based on these results, the functionalized SF (TiBP$\mathrm{SF})$ containing the designed peptide $\left[\mathrm{TS}\left[(\mathrm{AGSGAG})_{3} \mathrm{AS}\right]_{2} \mathrm{RKLPDAS}\right]_{8}$ was prepared from the cocoon of transgenic B. mori, which accelerates the ossific differentiation of MC3T3-E1 cells when coated on titanium substrates. Thus, TiBP-SF presents an alternative for endowing the surfaces of titanium materials with osseointegration functionality, which would allow the exploration of potential applications in the medical field.
\end{abstract}

Bio-functionalized titanium surfaces with modified silk fibroin carrying titanium binding motif to enhance the ossific differentiation of MC3T3-E1.

Mai Watanabe ${ }^{+++}$, Ujjal K. Bhawala ${ }^{\mathbb{I}}$, Shinji Takemoto\&, Norihiro Nishiyama\% ${ }^{\%}$, Yuichi Nakahara ${ }^{[?]}$, Kenichiro Tatematsu ${ }^{[?]}$, Hideki Sezuts ${ }^{[?]}$, Nobuo Kuwabarae, Tamiko Minamisawa ${ }^{+}$, Kiyotaka Shiba ${ }^{+*}$ and Tetsuo Asakura ${ }^{++}$

${ }^{+}$Division of Protein Engineering, Cancer Institute, Japanese Foundation for Cancer Research, 3-8-31 Ariake, Koto, Tokyo 125-8550, Japan, ${ }^{++}$Department of Biotechnology, Tokyo University of Agriculture and Technology, 2-24-16 Naka-cho, Koganei, Tokyo 184-8588, Japan, IDepartment of Biochemistry and Molecular Biology, and Research Institute of Oral Science, Nihon University School of Dentistry at Matsudo, 2-870-1 Sakae-cho Nishi, Matsudo, Chiba 271-8587, Japan, ${ }^{\&}$ Department of Biomedical Engineering, Iwate Medical University, Iwate 028-3694, Japan, ${ }^{\%}$ Department of Dental Biomaterials, Nihon University School of Dentistry at Matsudo, 2-870-1 Sakae-cho Nishi, Matsudo, Chiba 271-8587, Japan, [?] Transgenic Silkworm Research Unit, National Agriculture and Food Research Organization,1-2 Owashi, Tsukuba, Ibaraki 
305-8634, Japan, ¿Gunma Sericultural Technology Center, 2326osteo-2 Soja-machi, Maebashi, Gunma 3710852, Japan

\section{ABSTRACT. min-TBP-1 modified silk fibroin}

Silk fibroin (SF) from Bombyx mori has superior properties as both a textile and a biomaterial, and has been used to functionalize the surfaces of various medical inorganic materials including titanium (Ti). In this paper, we endowed SF with reversible binding ability to Ti by embedding a titanium binding motif (minTBP-1, RKLPDA). Artificial SF proteins were first created by conjugating gene cassettes for SF motif (AGSGAG) and minTBP-1 motif with different ratios, which have been shown to bind reversibly to Ti surfaces in quartz crystal microbalance analyses. Based on these results, the functionalized SF (TiBP$\mathrm{SF})$ containing the designed peptide $\left[\mathrm{TS}\left[(\mathrm{AGSGAG})_{3} \mathrm{AS}\right]_{2} \text { RKLPDAS }\right]_{8}$ was prepared from the cocoon of transgenic B. mori, which accelerates the ossific differentiation of MC3T3-E1 cells when coated on titanium substrates. Thus, TiBP-SF presents an alternative for endowing the surfaces of titanium materials with osseointegration functionality, which would allow the exploration of potential applications in the medical field.

KEYWORDS. Peptide aptamer, transgenic silk fibroin, artificial protein, biomaterial, 13C solid-state NMR

Running title. minTBP-1 functionalized silk fibroin.

\section{INTRODUCTION}

"Motif" is the versatile functional unit for constructing artificial biomacromolecules. In some cases, motif can endow non-biomolecules with its assigned functions, while in other cases different motifs can be combined to create artificial proteins having novel combinations of functions (Shiba, 2010). Motif sequences are identified both from natural sequences of proteins and from in vitro evolution systems. In the latter cases, a phage display system (Scott \& Smith, 1990)) has been employed to create an artificial peptide that binds to biomolecules and non-biological materials such as inorganic materials. The hexapeptidic RKLPDA sequence is one such inorganic material binding peptides. It was originally isolated as a 12-mer peptide binder to a titanium (Ti) surface by using a peptide display system (Sano \& Shiba, 2003). Subsequent analyses have revealed that the N-terminal RKLPDA (termed minTBP-1) is both necessary and sufficient for the binding (Sano, Sasaki, \& Shiba, 2005). This minTBP-1 motif has been widely employed as an appendix to provide an affinity to Ti in ferritin (Sano, Ajima, et al., 2005), artificial matrix proteins (Kokubun, Kashiwagi, Yoshinari, Inoue, \& Shiba, 2008), BMP-2 (Kashiwagi, Tsuji, \& Shiba, 2009), antimicrobial peptide (Geng et al., 2018; Yoshinari, Kato, Matsuzaka, Hayakawa, \& Shiba, 2010), calcification protein (Tsuji, Oaki, Yoshinari, Kato, \& Shiba, 2010), DNA-polymerase (Nishida et al., 2015), carbon nanomaterial-binding peptide (Kokubun, Matsumura, Yudasaka, Iijima, \& Shiba, 2018), and self-assembled chemical compounds (Ikemi et al., 2010). Interestingly, it has been revealed that the interaction between minTBP-1 and the surfaces of Ti is governed by reversible interactions (Brandt \& Lyubartsev, 2015; Hayashi et al., 2009; Sano, Ajima, et al., 2005; Schneider \& Ciacchi, 2012; Skelton, Liang, \& Walsh, 2009). In biological systems, weak, specific, reversible binding plays a pivotal role in various biological activities. Indeed, previous studies have shown certain biological activities has been enhanced by adding minTBP-1 to parental biomolecules(Kashiwagi et al., 2009; Kokubun et al., 2008).

Silk fibroin (SF) from Bombyx mori possesses many superior and inherent properties as a biomaterial, including advantageous mechanical properties, environmental stability, biocompatibility, low immunogenicity, and biodegradability (Aigner, DeSimone, \& Scheibel, 2018; Asakura \& Kaplan, 1994; Asakura, Tanaka, \& Tanaka, 2019; Koeppel \& Holland, 2017; Koh et al., 2015; Velema \& Kaplan, 2006; Vepari \& Kaplan, 2007). SF fiber has been used in sutures in the surgical field for more than 2,000 years (Thurber, Omenetto, \& Kaplan, 2015). Recently, the representative repeating unit of the crystalline fraction (56\% of whole SF) (Strydom, Haylett, \& Stead, 1977; Zhou et al., 2001; Zhou et al., 2000), AGSGAG sequence, has been used as a motif to create artificial SFs (Asakura et al., 2005; Asakura \& Yao, 2002; Yu Suzuki, Aoki, Nakazawa, Knight, \& Asakura, 2010; Yao, Ohgo, Sugino, Kishore, \& Asakura, 2004). Motif-based artificial protein constructions provide us with opportunities to create artificial biomolecules having novel biological activities 
or novel combinations of exiting activities (M. Yang \& Asakura, 2005; Mingying Yang, Kawamura, Zhu, Yamauchi, \& Asakura, 2009; M. Yang, Muto, Knight, Collins, \& Asakura, 2008; M. Yang, Tanaka, et al., 2008; M. Yang, Yamauchi, Kurokawa, \& Asakura, 2007). However, the production of these artificial proteins has generally been dependent on microorganisms or cell culture systems, which are obstacles to bulk production.

Recently, a germ line transformation method for the silkworm has been developed using the transposon piggyback (Kojima et al., 2007; Tamura et al., 2000). This enabled the production of functionalized transgenic (TG) SF in a large quantity such as cell-adhesive silks (Asakura et al., 2014; Yanagisawa et al., 2007), colored fluorescent silk (Iizuka et al., 2013), calcium binding silk (Nagano et al., 2011), and silk better suited to artificial blood vessels (Saotome et al., 2015). Such an improvement of the properties of SF for biomaterials has been attained by incorporating suitable DNA sequences. SF consists of a heavy chain (H-chain) and light chain (L-chain) connected by a disulfide bond, as well as a glycoprotein named P25. It is secreted into the posterior silk gland and is thought to be assembled into a high molecular mass elementary unit with a ratio of 6:6:1 (Couble, Chevillard, Moine, Ravel-Chapuis, \& Prudhomme, 1985; Takei, Kikuchi, Kikuchi, Mizuno, \& Shimura, 1987; Tanaka et al., 1999; Tanaka, Mori, \& Mizuno, 1993). The new gene that follows the SF gene is expressed as a new functionalized SF in the posterior silk gland. Subsequently, the SF stored in the middle silk gland is spun out through the anterior silk gland and converted into SF fibers, being coated by silk sericin that emerges in the middle silk gland. After removal of silk sericin by a degumming process, we obtained pure SF. There are many advantages in preparing functionalized SF suitable for biomaterials by the TG technique: (1) the TG silkworms are easy to handle and the larvae are well adapted for artificial rearing; (2) the adult moths cannot fly away and therefore cannot live in the wild; (3) the expression of the recombinant silk proteins can be confirmed visually by fusion of green fluorescent proteins as a marker.

We were interested in the possibility that a combination of the AGSGAG and minTBP-1 motifs could further enhance the functionality of SF when used as a coating agent for titanium substrates. While titanium has already been widely used in dental implants, artificial joints, and vessel stents (Brunette, Tengvall, Textor, \& Thomsen, 2001), further improvement of its biocompatibility is still required (Pagel et al., 2016; Schuler et al., 2006; Vidal et al., 2013; Zhang, Zhang, Zhu, Kang, \& Neoh, 2008). In the present study, we first synthesized artifice polypeptides containing both AGSGAG and minTBP-1 motifs, and confirmed their reversible interacting ability to titanium, which characterizes the minTBP-1 motif. Then, we constructed the transgenic B. morithat spins the cocoon containing the artificial SF. The modified SF prepared from the cocoons enhanced the ossific differentiation of MC3T3-E1 cells grown on the titanium plates coated by the artificial SF. The binding mechanism of silk-TBP on the surface of $\mathrm{TiO}_{2}$ nanoparticles was examined briefly using the model peptides made from the AGSGAG and minTBP-1 motifs, and ${ }^{13} \mathrm{C}$ solid-state NMR.

\section{MATERIALS AND METHODS}

\section{Production of silk-like proteins, TS[(AGSGAG) $\left.{ }_{3} \mathrm{AS}\right]_{\mathrm{n}}$ RKLPDAS and TS[(AGSGAG) $\left.{ }_{3} \mathrm{AS}\right]_{\mathrm{n}}$ by Escherichia coli.}

The recombinant silk-like proteins TS[(AGSGAG) $\left.{ }_{3} \mathrm{AS}\right]_{\mathrm{n}}$ RKLPDAS $(\mathrm{n}=2$ and 4$)$ and TS[(AGSGAG) $\left.)_{3} \mathrm{AS}\right]_{\mathrm{n}}$ ( $\mathrm{n}=2$ and 4 ) were prepared according to the method described previously (Yanagisawa et al., 2007; M. Yang \& Asakura, 2005; Mingying Yang et al., 2009; M. Yang, Muto, et al., 2008; M. Yang, Tanaka, et al., 2008; M. Yang et al., 2007). Here, (AGSGAG) $)_{3}$ (Bc3) and RKLPDA represent the crystalline region of SF and minimal sequence of titanium binding peptide, respectively. The construction scheme is shown in Figure 1a. The pUC-Bc3 is the recombinant vector, in which a single unit of DNA sequence coding (AGSGAG) ${ }_{3} \mathrm{AS}$ was inserted into pUC118 vector plasmid (Yanagisawa et al., 2007; M. Yang \& Asakura, 2005). Because this unit contains Spe I and Nhe I restriction enzyme recognition sites, and because these enzymes produce complemental sticky ends, directional multiplexing of the unit is possibly though repeated cut-and-paste manipulations (Prince, McGrath, DiGirolamo, \& Kaplan, 1995; M. Yang \& Asakura, 2005). In this study, we constructed 2-mer and 4-mer of [(AGSGAG) $\left.)_{3} \mathrm{AS}\right]_{\mathrm{n}}$ repeats, which were named pUC-(Bc3) 2 and pUC-(Bc3) ${ }_{4}$, respectively. To add RKLPDA motif at the end of repeats of (AGSGAG) ${ }_{3}$ AS, oligonucleotide KY-1775, pCTAGTCGGAAGCTGCCCGACG, and pCTAGCGTCGGGCAGCTTCCGA were annealed and ligated into the Nhe I site of pUC-(Bc3) 2 and pUC-(Bc3) ${ }_{4}$ to obtain pUC- $(\mathrm{Bc} 3)_{2} \mathrm{~T}$ and $\mathrm{pUC}-(\mathrm{Bc} 3)_{4} \mathrm{~T}$. Integrities 
of constructed artificial genes were confirmed by sequencing using the Dye Terminator Cycle Sequencing Quick Start Kit (Beckman Coulter, Brea, CA). For the expression in Escherichia coli, the inserts of these four plasmids were digested by Bam $\mathrm{HI}$ and Hind III, and were re-cloned into the same sites of the expression vector pET30a (Nobagen Inc Darmstadt, Germany) to obtain pET-(Bc3) $)_{2}$, pET-(Bc3) $)_{4}$ pET-(Bc3) 2 T, and pET-(Bc3) $)_{4} \mathrm{~T}$. In pET30a vectors, artificial silk fibroin proteins are expressed as the fusion proteins that carry a vector derived 6xHis-tag sequence at the N-terminal.

Because the pET30a vector is driven by a T7 promoter, the expression vectors were introduced in the $E$. coli strain BL21(DE3)pLysS (Nobagen Inc.), which has T7 polymerase, and the transformed cells were grown in 200-500 mL of LB (Sambrook, Fritsch, \& Maniatis, 1989) containing kanamycin and chloramphenicol at 37 ${ }^{\circ} \mathrm{C}$. At $\mathrm{OD}_{660}=0.5$, isopropyl $\beta$-D-1 thiogalactopyranoside (IPTG) was added to a final concentration of 1 $\mathrm{mM}$ to induce protein expression for $4 \mathrm{~h}$. After induction, cells were harvested and frozen and stored at -80 ${ }^{\circ} \mathrm{C}$ until purification. The protein expression was induced at $25{ }^{\circ} \mathrm{C}$ by adding IPTG to a final concentration of $1 \mathrm{mM}$. The recombinant proteins were purified by nickel-chelate chromatography using an ÄKTA explorer 10S/100 (GE Healthcare, Waukesha, WI, USA) column according to the manufacturer's protocol. The optimized conditions for elution were $15 \mathrm{mM}$ imidazole, $\mathrm{pH} 4.5$, and $50{ }^{\circ} \mathrm{C}$. The eluted protein solutions $(6-8 \mathrm{~mL})$ were dialyzed against $10 \mathrm{mM} \mathrm{NaH} \mathrm{PO}_{4}, \mathrm{pH} 8.0$ and $100 \mathrm{mM} \mathrm{NaCl}$ using a Slide-A-Lyzer Dialysis Cassette (3,500 MWCO, Pierce, Waltham, MA), followed by concentration into $500 \mu \mathrm{L}$ by using Amicon Ultra Centrifugation Filters-4 (Merck Millipore, Billerica, MA). The purified proteins from pET-(Bc3) 2 , pET-(Bc3) pET- $(\mathrm{Bc} 3)_{2} \mathrm{~T}$, and pET- $(\mathrm{Bc} 3)_{4} \mathrm{~T}$ were termed $(\mathrm{Bc} 3)_{2},(\mathrm{Bc} 3)_{4},(\mathrm{Bc} 3)_{2} \mathrm{~T}$, and $(\mathrm{Bc} 3)_{4} \mathrm{~T}$, respectively (Figure 1 a).

\section{QCM analyses.}

Quartz Crystal Microbalance (QCM) measurements were carried out on Qsense D300 equipment with a Ti sensor (Q-Sense, Vastra Frolunda) that was intensively cleaned with a UV-ozone ProCleaner system (BioForce Nanosciences, Ames, IA) prior to use. Before measurements, the Ti-sensor and the chamber were equilibrated in $50 \mathrm{mM}$ Tris- $\mathrm{HCl}(\mathrm{pH} 8.0)$ and $150 \mathrm{mM} \mathrm{NaCl}$ (TBS) containing $0.05 \%$ polyoxyethylene sorbitan monolaurate (Tween 20) (TBST) at $25{ }^{\circ} \mathrm{C}$. The proteins were prepared in a $2 \mathrm{~mL}$ volume at a concentration of $0.5 \mu \mathrm{M}$ in TBST. The data were obtained and analyzed by Q soft 301 and q-tool (Q-Sense).

\section{Construction of transgenic silk worm that spins the cocoons containing minTBP-1 appended silk fibroin (TiBP-SF).}

To introduce the RKLPDA motif (minTBP-1) into the SF heavy chain (HC), a DNA fragment coding $\left[\mathrm{TS}\left[(\mathrm{AGSGAG})_{3} \mathrm{AS}\right]_{2} \text { RKLPDA }\right]_{8}$ was synthesized (GenScript, Piscataway, NJ, USA) and inserted into the Bam HI and Sal I sites of plasmid pHC-EGFP (Kojima et al., 2007). The resultant plasmid was digested with $A s c \mathrm{I}$ and Fse I and inserted into the $A s c$ I and Fse I sites of the plasmid pBac[3xP3-EGFPafm](Horn, Schmid, Pogoda, \& Wimmer, 2002) to produce the vector plasmid pBac[HC-TiBP-3xP3EGFP] (Figure $1 \mathrm{~b}$ ). TG silkworms were produced by injecting the vector plasmid pBac[HC-TiBP-3xP3EGFP] into the eggs of silk worms in order to produce TG silkworms, as reported previously (Tamura et al., 2000). TG silkworms were established using a non-diapausing strain (w1-pnd) and were mated with the diapausing strain (w1) to maintain TG silkworms as diapausing strains. The silkworms were reared on an artificial diet (Nosan Corporation, Yokohama, Japan) or on fresh mulberry leaves at $25{ }^{\circ} \mathrm{C}$. Due to the poor yield and robustness of the silk of TG silkworm strains, they were backcrossed repeatedly with the commercial strains Gunma and 200, which have been shown to have high silk productivity. The resulting hybrid strains were then used for mass rearing of silkworms and collection of silk from the cocoons. The wild-type B. mori SF was used for comparison with the TG SF (TiBP-SF). The SF and TiBP-SF were dissolved by lithium bromide and desalinated using PD-10 column (GE Healthcare, Buckinghamshire, UK). Then, the samples were analyzed by $4 \%-12 \%$ gradient SDS-PAGE. The gel was stained with Coomassie Brilliant Blue R250 or transferred to polyvinylidene fluoride (PVDF) membranes. The membrane was treated with an anti-His tag antibody (A190-214A, BETHYL, Montgomery, USA). The immunoreactive bands were visualized using ECL Plus (GE Healthcare, Buckinghamshire, UK) and an LAS-3000 image analyzer (Fujifilm, Tokyo, Japan). 


\section{Surface modification of the Ti surface with SF or TiBP-SF.}

Pure wrought Ti disks $(\varnothing 7 \mathrm{~mm} \times 1 \mathrm{~mm})$ were purchased from Furuuchi Chemistry (Tokyo, Japan). The surface of each Ti disk was polished with a sequence of 320-, 600-, and 1200-grit silicon carbide papers (RIKEN, Saitama, Japan) under a stream of water. The polished Ti surface was used after being rinsed with ultrapure water $\left(\mathrm{Milli}^{\circledR}{ }^{\circledR}\right)$, ultrasonically cleaned with acetone, and then dried at room temperature. For coating, the disk was immersed in $5 \mathrm{ml} 2$ mass\% SF or TiBP-SF aqueous solution at $20{ }^{\circ} \mathrm{C}$ for $24 \mathrm{~h}$. After being air-dried at $20{ }^{\circ} \mathrm{C}$ for $1 \mathrm{~h}$, the disk was rinsed with $70 \%$ ethanol and then air-dried again at $20{ }^{\circ} \mathrm{C}$ for $24 \mathrm{~h}$.

\section{Cell culture.}

Osteoblast-like cells from rat calvaria (MC3T3-E1) cells were cultured in sterile cell culture plates containing $\alpha$-minimal essential medium ( $\alpha$-MEM) with $10 \%$ heat-inactivated fetal bovine serum (FBS) (Biowest, Riverside, MO, USA), $2 \mathrm{mM}$ L-glutamine and $10 \mathrm{U} / \mathrm{mL}$ penicillin/streptomycin (Gibco, Grand Island, NY, USA) in a humidified $95 \%$ air $/ 5 \% \mathrm{CO}_{2}$ incubator at $37^{\circ} \mathrm{C}$. When the cells reached sub-confluence, they were harvested and sub-cultured. The cell suspension $\left(5.0 \times 10^{4}\right.$ cells $)$ was slowly dripped onto the substrates (non-coated, SF-coated and TiBP-SF coated) in 48-well plates. Three replicates of each sample were tested during the culture period. Plates were shaken using gentle agitation for $10 \mathrm{~min}$ and were then incubated for $3 \mathrm{~h}$ at $37^{\circ} \mathrm{C}$. Then, $0.5 \mathrm{~mL}$ of medium was added along the side of each well.

\section{Scanning electron microscopy observations.}

At the end of the various incubation times, the non-attached cells on the different substrates were removed from the substrates by rinsing twice with $0.1 \mathrm{M}$ sodium cacodylate buffered solution, dehydrated in a graded series of ethanol $(50 \%, 70 \%$, and $90 \%)$, and then placed in 100\% ethanol. The dehydrated samples were then immersed in tert-butyl alcohol under vacuum (FDU-1200, EYELA, Tokyo, Japan). The freeze-dried samples were mounted on aluminum stubs and were then sputter-coated with a gold-palladium alloy. Scanning electron microscope (SEM, S-2150, Hitachi, Tokyo, Japan) observations of each sample were then performed at numerous magnifications at $10 \mathrm{kV}$.

\section{ALP assay}

Next, $5 \times 10^{4}$ MC3T3-E1 cells/mL in $\alpha$-MEM were seeded in 6 -well plates overnight. The medium in each well was removed the next day and replaced with osteoblast differentiation-inducing medium (OIM) (MK430, Takara Bio Inc., Tokyo, Japan), and then incubated at $37{ }^{\circ} \mathrm{C}$ for 3 weeks in a $5 \% \mathrm{CO}_{2}$ incubator. Day 0 is the date the OIM medium was added. ALP activity was determined using an ALP assay kit (ab83369, Abcam, Cambridge, MA, USA) following the manufacturer's instructions. In brief, untreated control and NaF-treated MC3T3-E1 cells were homogenized in assay buffer after washing with cold PBS and centrifuged at $15,000 \mathrm{rpm}$ for $15 \mathrm{~min}$ at $4{ }^{\circ} \mathrm{C}$. For each measurement, the supernatants were added in triplicate in 96 -well plates and each well was brought to a total volume of $80 \mu \mathrm{L}$ with assay buffer, followed by the addition of 20 $\mu \mathrm{L}$ stop-solution for a background control. Standard curves were generated as detailed in the manufacturer's manual. The ALP activity of each sample was calculated based on a comparison between the standard and sample curves and is reported as Unit/mL $(\mathrm{U} / \mathrm{mL})$.

\section{Cell differentiation, Alizarin Red S staining, and quantification.}

Here, $5 \times 10^{4}$ MC3T3-E1cells/ml in $\alpha$-MEM were seeded overnight with SF or TiBP-SF. The medium was removed the next day, replaced with OIM, and incubated at $37{ }^{\circ} \mathrm{C}$ for 3 weeks in a $5 \% \mathrm{CO}_{2}$ incubator. Day 0 is the date the differentiation medium was added to cells. The entire medium was replaced every 3 days. Alizarin red S staining was performed to analyze calcium deposits. Cells were washed twice with Hanks balanced salt solution (HBSS) (Gibco 14025, Thermo Fisher Scientific, Waltham, MA, USA) and then fixed with $4 \%$ paraformaldehyde for 15 min. The cells were stained with $1 \%$ Alizarin Red S solution for 3 min at $37{ }^{\circ} \mathrm{C}$ and rinsed with distilled water to exclude non-specific staining. For quantitation, cells stained with Alizarin red were de-stained with 10\% cetylpyridinium chloride (Sigma-Aldrich, Saint Louis, MO, USA) for $15 \mathrm{~min}$, after which the extracted stain was transferred to 96 -well plates, and the absorbance at $562 \mathrm{~nm}$ 
was measured using a microplate reader. After 2 and 3 weeks of osteogenic induction, the level of OC in the supernatant was directly measured using an ELISA kit (USCN Life Science, Wu Han, China) according to the manufacturer's instructions and a microplate reader at $450 \mathrm{~nm}$. The assays were performed in triplicate.

\section{Quantitative RT-PCR analysis.}

At weeks 2 and 3 after incubation with OIM, total RNAs were isolated using an miRNeasy Mini kit (Qiagen, Hilden, Germany). First-strand cDNAs were synthesized from $1 \mu \mathrm{g}$ of each total RNA using Super Script VILO Master Mix (Life Technologies, Carlsbad, CA, USA). One $\mu \mathrm{L}$ of each cDNA was subjected to realtime RT-PCR using TaqMan Gene Expression Assays (Applied Biosystems, Foster City, CA, USA) for Runx2 (Mm00501584_m1), Osterix (Mm04209856_m1), ALP (Mm04209856_m1), Collagen Type 1 (Col I) (Mm04209856_m1), OPN (Mm00436767_m1) and OC (Mm03413826_m1), and Pre-Developed TaqMan Assay Reagents (Applied Biosystems) for $\beta$-actin (Mm02619580_g1) as an internal control. Two-step PCR cycling was carried out as follows: 2 min at $50{ }^{\circ} \mathrm{C}$ for 1 cycle, 10 min at $95{ }^{\circ} \mathrm{C}$ for 1 cycle, then $15 \mathrm{~s}$ at $95{ }^{\circ} \mathrm{C}$ and 1 min at $60{ }^{\circ} \mathrm{C}$ for 40 cycles. Two independent measurements were averaged, and relative mRNA expression levels were calculated as a ratio to $\beta$-actin expression of each sample.

\section{Statistical analysis.}

All quantitative data are expressed as means \pm SD. Statistical analyses were performed using the statistics program SPSS 20. Results were analyzed by one-way ANOVA, followed by post hoc tests for pair-wise comparisons (Tukey's test). Differences were considered to be significant for $\mathrm{p}<0.05$.

\section{Synthesis of the Model Peptides of the AGSGAG and minTBP-1 motifs.}

To examine the binding mechanism of silk-TBP on the surface of $\mathrm{TiO}_{2}$ nonoparticles, the model peptides of the AGSGAG and minTBP-1 motifs, i.e., RKLPDA (minTBP-1), (AGSGAG) $)_{2}$, AGSGAGGRKLPDAGGAGSGAG (Silk-TBP), and AGSG $\left[1-{ }^{13} \mathrm{C}\right]$ AGGRKLPD $\left[3-{ }^{13} \mathrm{C}\right]$ AGGAGSGAG $\left({ }^{13} \mathrm{C}\right.$ Silk-TBP) were synthesized in a stepwise fashion on Fmoc-amino acid-PEG-PS resin by a Pioneer Peptide Synthesis System (PE Biosystems, USA) using Fmoc solid phase method in our laboratory (Asakura et al., 2005; Asakura \& Yao, 2002; Yu Suzuki et al., 2010; Yao et al., 2004). The purity was more than 95\%, as verified by high-performance liquid chromatography and ${ }^{13} \mathrm{C}$ solution NMR. The $\left[1-{ }^{13} \mathrm{C}\right] \mathrm{Ala}\left(99.9 \%{ }^{13} \mathrm{C}\right.$ enrichment) and $\left[3-{ }^{13} \mathrm{C}\right]$ Ala $(99.9 \%$ ${ }^{13} \mathrm{C}$ enrichment) were purchased from Cambridge Isotopes Laboratories, Andover, MA, USA.

\section{Preparation of $\mathrm{TiO}_{2}$ particles with ${ }^{13} \mathrm{C}$ Silk-TBP on the surface.}

The nanoparticles of $\mathrm{TiO}_{2}$ (Aeroxide $\mathrm{TiO}_{2} \mathrm{P} 25$ ), which were kindly provided by NIPPON AEROSIL co., $\mathrm{JP}$, had an average particle size of $21 \mathrm{~nm}$ and a surface area of $50 \pm 15 \mathrm{~m}^{2} / \mathrm{g}$. The $\mathrm{TiO}_{2}$ nanoparticles were suspended in water and sonicated twice for $30 \mathrm{~min}$ with a $50 \%$ duty cycle. The suspension was then centrifuged at 10,000 rpm for $15 \mathrm{~min}$, and the precipitated $\mathrm{TiO}_{2}$ nanoparticles were washed in distilled water. This process was repeated, and the particles were dried overnight. The dried particles were suspended in 20 $\mathrm{mM}$ phosphate buffer at $\mathrm{pH}=7.0$ and sonicated again for $10 \mathrm{~min}$ with a $50 \%$ duty cycle. The peptides (TBP, $\left(\right.$ AGSGAG) 2 , and Silk-TBP) were dissolved in $20 \mathrm{mM}$ phosphate buffer and mixed with the suspended $\mathrm{TiO}_{2}$ nanoparticle solutions, respectively. The weight ratio of the peptide and suspended $\mathrm{TiO}_{2}$ nanoparticle was 1:1 for each case. Finally, the state of dispersion of the mixture after standing overnight was observed.

\section{Solid-state ${ }^{13} \mathrm{C}$ CP/MAS NMR Measurement .}

The ${ }^{13} \mathrm{C}$ Silk-TBP $(20 \mathrm{mg})$ was dissolved in $20 \mathrm{mM}$ phosphate buffer at $\mathrm{pH}=7.0(10 \mathrm{ml})$ and mixed with the $\mathrm{TiO}_{2}$ nanoparticles $(50 \mathrm{mg})$. The solution was stirred for $4 \mathrm{~h}$ at $100 \mathrm{rpm}$ to reach equilibrium. Then equilibrated. Then the suspension was centrifuged at 10,000 rpm for $10 \mathrm{~min}$ and excess peptide dissolved in the supernatant was removed. This process was repeated. Thus, $\mathrm{TiO}_{2}$ particles with ${ }^{13} \mathrm{C}$ Silk-TBP adsorbed on the surface were obtained after drying. The ${ }^{13} \mathrm{C} \mathrm{CP} / \mathrm{MAS}$ NMR spectra of the ${ }^{13} \mathrm{C}$ Silk-TBP and ${ }^{13} \mathrm{C}$ Silk-TBP adsorbed on the surface of $\mathrm{TiO}_{2}$ nanoparticles were recorded on a Bruker Avance 400 NMR spectrometer with an operating frequency of $100.0 \mathrm{MHz}$ for ${ }^{13} \mathrm{C}$ at a sample spinning rate of $8 \mathrm{kHz}$ in a $4 \mathrm{~mm}$ diameter $\mathrm{ZrO}_{2}$ rotor. The numbers of scans were $1 \mathrm{~K}$ for ${ }^{13} \mathrm{C}$ Silk-TBP and $40 \mathrm{~K}$ for ${ }^{13} \mathrm{C}$ Silk-TBP adsorbed 
on the $\mathrm{TiO}_{2}$ nanoparticles. The pulse delay was $5 \mathrm{~s}$ and contact time was $2 \mathrm{~ms}$. The ${ }^{13} \mathrm{C}$ chemical shifts were referenced to TMS using adamantane as a secondary standard $\left({ }^{13} \mathrm{CH}\right.$ peak at $\left.28.8 \mathrm{ppm}\right)$.

\section{RESULTS AND DISCUSSION}

\section{QCM analyses}

Designer proteins $(\mathrm{Bc} 3)_{2},(\mathrm{Bc} 3)_{4},(\mathrm{Bc} 3)_{2} \mathrm{~T}$, and $(\mathrm{Bc} 3)_{4} \mathrm{~T}$ (Figure 1 a) were synthesized and purified as described in MATERIALS AND METHODS. Using QCM, the mode of interactions between the crated artificial proteins and titanium surface was assessed. In the QCM assay, binding of molecules on the surface of the sensor decreases the resonance frequency of the sensor and detachment of molecules from the surface is observed as the resonance frequency increases. Steps of QCM measurements are schematically illustrated in Figure $2 \mathrm{a}$. First, the Ti sensor was equilibrated with water for 30-60 min and the measurement was started $($ time $=0$ ). After $5 \mathrm{~min}$, TBST (a solution buffer of the proteins) was injected 3 times (time $=5,10$, and $15 \mathrm{~min}$ ). Then, protein solution was injected into the measurement chamber (time $=20 \mathrm{~min}$ ). After $30 \mathrm{~min}$, the sensor was washed with TBST 3 times $($ time $=50,55$, and $60 \mathrm{~min}$ ), followed by washing with water 3 times (time $=65,70$, and $75 \mathrm{~min}$ ). Results obtained from $(\mathrm{Bc} 3)_{2}$ and $(\mathrm{Bc} 3)_{2} \mathrm{~T}$ are shown in Figure $2 \mathrm{~b}$. Injections of the protein solutions rapidly decreased the resonance frequency of the sensor, indicating that both $(\mathrm{Bc} 3)_{2}$ and $(\mathrm{Bc} 3)_{2} \mathrm{~T}$ have bound to the surfaces of Ti. Because TBST washing only slightly increased the frequency, the binding of these proteins to $\mathrm{Ti}$ is stable under the conditions. When the measurement sensor was washed with water $($ time $=65 \mathrm{~min}$ ), an increase of frequencies was observed, which was due to buffer change (not detachment of proteins from the sensor). When the rates of frequency increase in water were compared between $(\mathrm{Bc} 3)_{2}$ and $(\mathrm{Bc} 3)_{2} \mathrm{~T}($ time $=65-80 \mathrm{~min})$, it can be recognized that $(\mathrm{Bc} 3)_{2} \mathrm{~T}$ was detaching faster than $\mathrm{B}(\mathrm{Bc} 3)_{2}$. Similar results were obtained from $(\mathrm{Bc} 3)_{4}$ and $(\mathrm{Bc} 3)_{4} \mathrm{~T}$ (Figure $2 \mathrm{c}$ ).

Construction of transgenic Bombyx mori that spins the cocoons containing the functionalized silk fibroin (TiBP-SF).

The QCM analyses indicated that the artificial proteins composed of SF core motifs and minTBP-1 motif have the abilities to bind to (and detach from) the titanium surface. To evaluate the effect of the appended minTBP-1 motif on the nourishing ability of SF for cells, we decided to construct the largescale production system for SF-minTBP-1 proteins. For this experiment, we selected the $(\mathrm{Bc} 3)_{2} \mathrm{~T}=$ $\left[\mathrm{TS}\left[(\mathrm{AGSGSG})_{3} \mathrm{AS}\right]_{2}\right.$ RKLPDA] as a core unit. This was because in the QCM experiments, $(\mathrm{Bc} 3)_{2} \mathrm{~T}$ bound in larger quantities and detached faster (especially in water) than $(\mathrm{Bc} 3)_{4} \mathrm{~T}$, suggesting the properties of minTBP-1 was more manifested in this formula.

We have already established the transgenic B. mori system, which has enabled us to prepare large amounts of engineered SF (Asakura et al., 2014; Iizuka et al., 2013; Kojima et al., 2007; Nagano et al., 2011; Saotome et al., 2015; Tamura et al., 2000; Yanagisawa et al., 2007). In this study, a DNA fragment coding $\left[\mathrm{TS}\left[(\mathrm{AGSGSG})_{3} \mathrm{AS}\right]_{2} \mathrm{RKLPDA}\right]_{8}\left((\mathrm{Bc} 3)_{2} \mathrm{~T}\right)$ was inserted into the plasmid pHC-EGFR(Kojima et al., 2007) to construct pBac[HC-TiBP-3xP3EGFP] (Figure $1 \mathrm{~b}$ ), which was injected into the eggs of the silkworm, and transgenic silkworms were selected as described previously (Kojima et al., 2007; Tamura et al., 2000; Yanagisawa et al., 2007). The established transgenic silkworms spin cocoons that are apparently indistinguishable from wild-type samples (data not shown). From the cocoons, SF proteins were prepared following standard procedures described in MATERIALS AND METHODS, and the obtained fibroin proteins (named TiBP-SF) were analyzed by SDS-PAGE followed by CBB staining (Figure 3 a). From the TiBP-SF sample, in addition to SF H-chain and SF L-chain proteins, an additional protein band was observed that was not detected from the wild-type SF sample. Western blotting using an anti-His tag antibody confirmed that the protein was derived from a transgenic gene (Figure $3 \mathrm{~b}$ ).

The apparent molecular weight of the appendix protein $(75 \mathrm{~K})$ was larger than that of the estimated molecular weight $(52 \mathrm{kD})$. Similar abnormal mobilities of the modified SFs in SDS-PAGE have also been reported in other experiments (Asakura et al., 2014; Iizuka et al., 2013; Kojima et al., 2007; Saotome et al., 2015; Teule et al., 2012; Yanagisawa et al., 2007), which may be due to either skewed amino acid compositions of the proteins or particular secondary structures. Because the ratio of minTBP-1 motif to SF motif should be 
extremely small (approximately 0.1 to $0.9 \%$ in a similar system (Yanagisawa et al., 2007)) compared to the model artificial proteins used in the experiments of Figure 2, we were interested in the effect of minTBP-1 on the binding ability of SF to titanium. As shown in Figure 4 a, QCM analyses indicated that TiBP-SF decreased the amounts of protein absorbed on the titanium sensor, which agreed well with the results obtained from $(\mathrm{Bc} 3)_{2} \mathrm{~T}$ and $(\mathrm{Bc} 3)_{4} \mathrm{~T}$. This means that with a decreased ratio of minTBP-1/silk motif, the minTBP-1 motif masks the binding ability of sill peptide to the material surface. Thus, doping SF with minTBP-1 dramatically changed the binding properties of SF. This notion was further confirmed by the observation that the Silk model peptide (AGSGAG) $)_{2}$ was not able to disperse Ti particles in aqueous solution, whereas Silk-TBP model peptide AGSGAGGRKLPDAGGAGSGAG can endow the Ti particle with dispersibility similar to the mimTBP-1 peptide (Figure $4 \mathrm{~b}$ ).

\section{Osteoblast differentiation on the TiBP-SF-coated titanium surfaces.}

The above data demonstrated that TiBP-SF and SF have distinct behaviors in terms of binding to the titanium surface. However, it was not clear whether the altered properties of TiBP-SF can improve the performance of titanium for medical devices. To address this question, we performed biological assessments using an osteoblastic cell line (MC3T3-E1), which has often been used to evaluate osteoblast differentiation. After coating titanium plates with either SF or TiBP-SF (as described in MATERIALS and METHODS), MC3T3-E1 was grown on the plates for 14 and 21 days in the differentiation-inducing medium (OIM). The morphologies of the cells on the plates were then observed by SEM. As shown in Figure 5 a, the enhanced differentiation of MC3T3-E1, which is characterized by an elongated sheet-like cell structures with multiple filopodia-like intercellular connections protruding from their leading edges, was evident after 21 days when the titanium plates were coated with TiBP-SF. Without coating (or SF-coating), these characteristic morphologies were not evident.

The formation of filopodia from MC3T3-E1 after 21 days of growth on the TiBP-SF coated Ti plate suggested the cells were differentiated into a hydroxyapatite-mineralizing state, which was further confirmed by the increased alkaline phosphatase (ALP) activity and osteocalcin (OC) production. As shown in Figure $5 \mathrm{~b}$, both the ALP activity and OC production from the cells grown on the TiBP-SF coated Ti substrate were the highest among the 3 groups after 21 days of growth. Moreover, the ALP activity of the SF group was lower than that of the TiBP-SF group $(\mathrm{p}<0.05)$, indicating that TiBP-SF was more beneficial than SF for inducing cell differentiation and promoting cell mineralization. The mineralization of MC3T3-E1 cells was also evaluated by alizarin red staining (Figure $5 \mathrm{c}$ ). Cells grown on TiBP-SF displayed higher mineralization capacities than those grown on SF $(\mathrm{p}<0.01)$, as well as the control after culture for 21 days. The calcified deposits were uniform and clustered in all locations. To evaluate the cell differentiation state in more detail, the expression levels of osteoblast-related genes (including Runx2, Osterix, OC, OPN, ALP, and Col I) were evaluated by real-time PCR analyses after culture for 14 and 21 days (Figure $5 \mathrm{~d}$ ). Runx2 and Osterix are master transcription factors involved in regulating the process of MC3T3-E1cell differentiation. After culture for 14 days, the expression levels of both the Runx2 and Osterix genes in cells cultured on TiBP-SF were up-regulated more than those cultured on SF or on the control. Although the expression level of the Runx2 gene decreased in all groups after culture for 21 days, the TiBP-SF group remained much higher than the SF group. A similar trend was also found for Osterix expression. The early markers of osteoblasts (such as the transcription of ALP and Col I) were also up-regulated after culture for 21 days on TiBP-SF compared with the other groups. Furthermore, culture on TiBP-SF up-regulated the mRNA expression levels of OC and OPN at most time intervals. Thus, TiBP-SF was shown to have an ability for enhancing the differentiation of an osteoblast model cell line in vitro .

\section{Conformations of ${ }^{13} \mathrm{C}$ Silk-TBP and ${ }^{13} \mathrm{C}$ Silk-TBP adsorbed on the surface of $\mathrm{TiO}_{2}$ nanoparti-} cles in the solid state.

To obtain further insights into the binding mechanisms of the SF-minTBP-1 proteins, we synthesized the ${ }^{13} \mathrm{C}$ -labeled model peptide for solid state NMR analyses. Figure 6 shows ${ }^{13} \mathrm{C}$ CP/MAS NMR spectra (10-70 ppm) of (a) ${ }^{13} \mathrm{C}$ Silk-TBP (AGSG $\left[1-{ }^{13} \mathrm{C}\right]$ AGGRKLPD $\left[3-{ }^{13} \mathrm{C}\right]$ AGGAGSGAG) and (b) ${ }^{13} \mathrm{C}$ Silk-TBP adsorbed on the surface of $\mathrm{TiO}_{2}$ nanoparticles together with the assignment (Asakura et al., 2005; Asakura \& Yao, 2002; 
Yu Suzuki et al., 2010; Y. Suzuki, Shindo, \& Asakura, 2016; Wishart, 2011; M. Yang \& Asakura, 2005; Yao et al., 2004). The chemical shifts and the assignments are summarized in Table 1. According to the chemical shifts of the peaks, Ala $\mathrm{C} \beta$ and Ala $\mathrm{C} \alpha$ carbons, the conformation of the ${ }^{13} \mathrm{C}$ Silk-TBP sample in a solid state is considered to be random coil. This is due to the sample preparation by freeze-dry treatment (Asakura et al., 2005; Yao et al., 2004). After adsorption treatment of the peptides on the surface of the $\mathrm{TiO}_{2}$ nanoparticles, a small ${ }^{13} \mathrm{C}$ labeled methyl peak of $\left[3{ }^{13} \mathrm{C}\right] \mathrm{Ala}^{13}$ residue in the partial sequence $\left(\mathrm{RKLPD}\left[3-{ }^{13} \mathrm{C}\right] \mathrm{A}\right)$ in the peptide could be still observed. Interestingly, the $\mathrm{Ala}^{13} \mathrm{C} \beta$ chemical shift changed from a random coil (16.3 $\mathrm{ppm})$ to an $\alpha$-helix (14.4 ppm) (Figure 6). Namely, the $\mathrm{Ala}^{13}$ residue adsorbed on the $\mathrm{TiO}_{2}$ particle took an $\alpha$-helix form. The $\alpha$-helix peak also became remarkably sharper compared to the Ala C $\beta$ random coil peak of the peptide before adsorption. This could indicate that the interaction between the minTBP-1 and the surfaces of $\mathrm{TiO}_{2}$ is governed by reversible interactions. In addition, relatively sharp peaks at 21.0 and $25.6 \mathrm{ppm}$ could be observed, which are assigned to the side chain carbons of natural abundant Leu and Lys residues in the sequence RKLPDA. Namely, the peak at $21.0 \mathrm{ppm}$ is assigned to the Leu $\mathrm{C}_{1}, \mathrm{C} \delta_{2}$, and Lys $\mathrm{C} \gamma$ carbons, and the peak at $25.6 \mathrm{ppm}$ to the Lys $\mathrm{C} \delta$ carbon (according to the chemical shifts). Thus, the Leu and Lys residues are considered to be attached to the surface of $\mathrm{TiO}_{2}$ particles, although the backbone peaks of these residues could not be observed.

\section{CONCLUSIONS}

By using a transgenic B. mori system, we synthesized the modified silk fibroin TiBP-SF, which is doped with an artificial protein composed of silk fibroin motif (AGSGAG) and titanium binding motif (RKLPDAS) in the $\left[\mathrm{TS}\left[(\mathrm{AGSGAG})_{3} \mathrm{AS}\right]_{2} \text { RKLPDAS }\right]_{8}$ formula. The TiBP-SF enhanced the ossific differentiation of osteoblastlike cells when coated on the surfaces of a titanium plate. Accordingly, TiBP-SF has potential applications in the medical field.

\section{Acknowledgments}

T. A. and K. S acknowledge the supports of a JSPS KAKENHI, Grant-in-Aid for Scientific Research (C), Grant Number JP19K05609 and Grant-in-Aid for Scientific Research (A), Grant Number 23240135, respectively.

\section{Figure captions}

Figure 1. (a) Construction flow of the recombinant plasmids from genetic blocks coding for the crystalline region of silk fibroin ((AGSGAG) $)_{3} \mathrm{AS}$, blue arrow) and for the minimal titanium binding motif (RKLPDA , orange arrow). B, N, S, and H representBam HI, Nhe I, Spe I, and Hind III, respectively. From the resultants plasmids, the His-tagged proteins, $(\mathrm{Bc} 3)_{2},(\mathrm{Bc} 3)_{4},(\mathrm{Bc} 3)_{2} \mathrm{~T}$, and $(\mathrm{Bc} 3)_{4} \mathrm{~T}$ were produced in BL21(DE3)pLysS and purified by nickel-chelate chromatography, whose domain structures are schematically illustrated by the colored ellipses (indicated in the inner box). (b) The structure of the vector for constructing the transgenic silkworm. The gene for $\left[\mathrm{TS}\left[(\mathrm{AGSGAG})_{3} \mathrm{AS}\right]_{2} \mathrm{RKLPDA}\right]_{8}$ is under the control of Fibroin $\mathrm{H}$ promoter. (c) The structure of proteins translated from pBac[HC-TiBP-3xP3EGFP], which has the Nterminal domain (NTD), the C-terminal domain (CTD), and C-terminal His-tag, which were derived from the parental vector, pBac[3xP3-EGFPafm] (Horn et al., 2002). Arrows indicate right and left arms of the transposon piggyBac. EGFP was used for screening the transgenic silkworm.

Figure 2. (a) Schematic drawings representing the changes in frequency ([?]f; left axis) of titanium sensor upon (i) buffer injection, (ii) sample injection, (iii) buffer wash and (iv) water wash in QCM analyses. (b) Changes in resonance frequency with $0.5 \mu \mathrm{m}(\mathrm{Bc} 3)_{2}$ (blue) and $(\mathrm{Bc} 3)_{2} \mathrm{~T}$ (green). (c) Changes in resonance frequency with $0.5 \mu \mathrm{m}(\mathrm{Bc} 3)_{4}$ (blue) and $(\mathrm{Bc} 3)_{4} \mathrm{~T}$ (green).

Figure 3. (a) SDS-PAGE and Coomassie Brilliant Blue R250 staining for the functionalized SF, TiBP-SF, and its parental SF. The arrow indicates the artificial protein containing $\left[\mathrm{TS}\left[(\mathrm{AGSGAG})_{3} \mathrm{AS}\right]_{2} \mathrm{RKLPDA}\right]_{8}($ Figure $1 \mathrm{c})$. The open circle, the closed circle, and the triangle indicate Fibroin H-chain protein, Fibroin L-chain protein, and Fibro hexamerin protein (Inoue et al., 2000), respectively. (b) Western blotting using anti-His antibody, which recognizes the C-terminal His-tag of the 
artificial SF.

Figure 4. (a) Changes in resonance frequency of titanium sensor with $1 \mathrm{mg} / \mathrm{mL}$ of SF (blue) and TiBPSF (green). Details of experimental procedures are described in Figure 1 caption and MATERIALS AND METHODS. (b) Dispersion of $\mathrm{TiO}_{2}$ particles $(21 \mathrm{~nm}$ ) with TBP (RKLPDA) peptide, Silk-TBP (AGSGAGGRKLPDAGGAGSGAG) peptide, Silk ((AGSGAG) $\left.)_{2}\right)$ peptide and no peptide (control). Details of experiments are described in MATERIALS AND METHODS.

Figure 5. (a) SEM images (magnification of 2000×) of non-coated (cont), SF-coated and TiBP-SF-coated polished Ti surfaces after cultivating MC3T3-E1 cells for 14 or 21 days. The bars indicate $10 \mu \mathrm{m}$. (b) Effects of TiBP-SF coating on the alkaline phosphatase (ALP) activity and the expression level of osteocalcin (OC) of MC3T3-E1 cells after 14 and 21 days incubation. Values are expressed as means $\pm \mathrm{SD}(\mathrm{n}=3)$. Asterisks indicate $\mathrm{P}<0.05$ in the t-test. (c) Effect of TiBP-SF coating on the mineralization in MC3T3-E1 cells. Cells were stained with Alizarin Red (left) and quantified as described in the MATERIALS AND METHODS after 14 and 21 days incubation. Asterisks indicate $\mathrm{P}<0.05$ in the t-test. (d) Expression levels of mRNA for Runx2, Osterix, ALP) Collagen Type I (Col I), Osteopontin (OPN) and OC, which were quantified by quantitative RT-PCR, in MC3T3-E1 cells after 14 and 21 days incubation on non-coated (control), SF-coated, and TiBP-SF-coated polished Ti surfaces. The relative mRNA expression levels were calculated as a ratio to $\beta$-actin expression of each sample. Values represent means \pm SD from three independent experiments. Asterisks indicate $\mathrm{P}<0.05$ in the t-test.

Figure 6. ${ }^{13} \mathrm{C}$ CP/MAS NMR spectra (10-70 ppm) of (a) ${ }^{13} \mathrm{C}$ Silk-TBP (AGSG[1- $\left.{ }^{13} \mathrm{C}\right]$ AGGRKLPD[3$\left.{ }^{13} \mathrm{C}\right]$ AGGAGSGAG) and (b) ${ }^{13} \mathrm{C}$ Silk-TBP adsorbed on the surface of $\mathrm{TiO}_{2}$ nanoparticles together with the assignments.

Table $1 .{ }^{13} \mathrm{C}$ chemical shifts and assignments of ${ }^{13} \mathrm{C}$ CP/MAS NMR spectra of (a) ${ }^{13} \mathrm{C}$

Silk-TBP and (b) ${ }^{13} \mathrm{C}$ Silk-TBP adsorbed on the surface of $\mathrm{TiO}_{2}$ nanoparticles.

Chemical Shift

Assignment

(a)

(b)

(b) $14.5 \mathrm{ppm}$

(a) $16.2 \mathrm{ppm}$

(b) $21 \mathrm{ppm}$

(b) $25.5 \mathrm{ppm}$

(a) $42 \mathrm{ppm}$ (broad)

(b) 42-43 ppm (broad)

(a) 49 ppm (broad)
Ala ${ }^{13} \mathrm{Cb} \quad$ a-helix

Ala ${ }^{13} \mathrm{Cb}$ random coil

Leu $\mathrm{Cd}_{1}, \mathrm{~d}_{2}$ Lys Cg

Lys Cd

Gly Ca

Gly Ca

Ala Ca random coil

\section{REFERENCES}

Aigner, T. B., DeSimone, E., \& Scheibel, T. (2018). Biomedical Applications of Recombinant Silk-Based Materials. Adv Mater, 30 (19), e1704636. doi:10.1002/adma.201704636

Asakura, T., Isozaki, M., Saotome, T., Tatematsu, K.-i., Sezutsu, H., Kuwabara, N., \& Nakazawa, Y. (2014). Recombinant silk fibroin incorporated cell-adhesive sequences produced by transgenic silkworm as a possible candidate for use in vascular graft. J. Mater. Chem. B, 2 (42), 7375-7383. doi:10.1039/c4tb01301h 
Asakura, T., \& Kaplan, D. L. (1994). Silk Production and Processing. In C. J. Arntzen (Ed.), Encyclopedia of Agricultural Science (Vol. 4, pp. 1): Academic Press Inc.

Asakura, T., Ohgo, K., Ishida, T., Taddei, P., Monti, P., \& Kishore, R. (2005). Possible implications of serine and tyrosine residues and intermolecular interactions on the appearance of silk I structure of Bombyx mori silk fibroin-derived synthetic peptides: high-resolution 13C cross-polarization/magic-angle spinning NMR study.Biomacromolecules, 6 (1), 468-474. doi:10.1021/bm049487k

Asakura, T., Tanaka, T., \& Tanaka, R. (2019). Advanced Silk Fibroin Biomaterials and Application to Small-Diameter Silk Vascular Grafts.ACS Biomaterials Science 63 Engineering, 5 (11), 5561-5577. doi:10.1021/acsbiomaterials.8b01482

Asakura, T., \& Yao, J. (2002). 13C CP/MAS NMR study on structural heterogeneity in Bombyx mori silk fiber and their generation by stretching. Protein Sci, 11 (11), 2706-2713. doi:10.1110/ps.0221702

Brandt, E. G., \& Lyubartsev, A. P. (2015). Molecular Dynamics Simulations of Adsorption of Amino Acid Side Chain Analogues and a Titanium Binding Peptide on the TiO2 (100) Surface. The Journal of Physical Chemistry C, 119 (32), 18126-18139. doi:10.1021/acs.jpcc.5b02670

Brunette, D. M., Tengvall, P., Textor, M., \& Thomsen, P. (2001).Titanium in Medicin . Berlin: Springer Verlag Berlin Heidelberg.

Couble, P., Chevillard, M., Moine, A., Ravel-Chapuis, P., \& Prudhomme, J. C. (1985). Structural organization of the P25 gene of Bombyx mori and comparative analysis of its 5' flanking DNA with that of the fibroin gene. Nucleic Acids Res, 13 (5), 1801-1814. doi:10.1093/nar/13.5.1801

Geng, H., Yuan, Y., Adayi, A., Zhang, X., Song, X., Gong, L., . . . Gao, P. (2018). Engineered chimeric peptides with antimicrobial and titanium-binding functions to inhibit biofilm formation on Ti implants. Mater Sci Eng C Mater Biol Appl, 82 , 141-154. doi:10.1016/j.msec.2017.08.062

Hayashi, T., Sano, K., Shiba, K., Iwahori, K., Yamashita, I., \& Hara, M. (2009). Critical amino acid residues for the specific binding of the Ti-recognizing recombinant ferritin with oxide surfaces of titanium and silicon. Langmuir, 25 (18), 10901-10906. doi:10.1021/la901242q

Horn, C., Schmid, B. G., Pogoda, F. S., \& Wimmer, E. A. (2002). Fluorescent transformation markers for insect transgenesis. Insect Biochem Mol Biol, 32 (10), 1221-1235. doi:10.1016/s0965-1748(02)00085-1

Iizuka, T., Sezutsu, H., Tatematsu, K.-i., Kobayashi, I., Yonemura, N., Uchino, K., . . Tamura, T. (2013). Colored Fluorescent Silk Made by Transgenic Silkworms. Advanced Functional Materials, 23 (42), 5232-5239. doi:10.1002/adfm.201300365

Ikemi, M., Kikuchi, T., Matsumura, S., Shiba, K., Sato, S., \& Fujita, M. (2010). Peptide-coated, selfassembled M12L24 coordination spheres and their immobilization onto an inorganic surface. Chemical Science, 1 (1), 68-71. doi:10.1039/C0SC00198H

Inoue, S., Tanaka, K., Arisaka, F., Kimura, S., Ohtomo, K., \& Mizuno, S. (2000). Silk fibroin of Bombyx mori is secreted, assembling a high molecular mass elementary unit consisting of H-chain, L-chain, and P25, with a 6:6:1 molar ratio. J Biol Chem, 275 (51), 40517-40528. doi:10.1074/jbc.M006897200

Kashiwagi, K., Tsuji, T., \& Shiba, K. (2009). Directional BMP-2 for functionalization of titanium surfaces. Biomaterials, 30 (6), 1166-1175. doi:10.1016/j.biomaterials.2008.10.040

Koeppel, A., \& Holland, C. (2017). Progress and Trends in Artificial Silk Spinning: A Systematic Review. ACS Biomaterials Science \&3 Engineering, 3 (3), 226-237. doi:10.1021/acsbiomaterials.6b00669

Koh, L.-D., Cheng, Y., Teng, C.-P., Khin, Y.-W., Loh, X.-J., Tee, S.-Y., . . Han, M.-Y. (2015). Structures, mechanical properties and applications of silk fibroin materials. Progress in Polymer Science, 46 , 86-110. doi:10.1016/j.progpolymsci.2015.02.001 
Kojima, K., Kuwana, Y., Sezutsu, H., Kobayashi, I., Uchino, K., Tamura, T., \& Tamada, Y. (2007). A new method for the modification of fibroin heavy chain protein in the transgenic silkworm. Biosci Biotechnol Biochem, 71 (12), 2943-2951. doi:10.1271/bbb.70353

Kokubun, K., Kashiwagi, K., Yoshinari, M., Inoue, T., \& Shiba, K. (2008). Motif-programmed artificial extracellular matrix.Biomacromolecules, 9 (11), 3098-3105. doi:10.1021/bm800638z

Kokubun, K., Matsumura, S., Yudasaka, M., Iijima, S., \& Shiba, K. (2018). Immobilization of a carbon nanomaterial-based localized drug-release system using a bispecific material-binding peptide.Int $J$ Nanomedicine, 13 , 1643-1652. doi:10.2147/IJN.S155913

Nagano, A., Tanioka, Y., Sakurai, N., Sezutsu, H., Kuboyama, N., Kiba, H., . . . Asakura, T. (2011). Regeneration of the femoral epicondyle on calcium-binding silk scaffolds developed using transgenic silk fibroin produced by transgenic silkworm. Acta Biomater, 7 (3), 1192-1201. doi:10.1016/j.actbio.2010.10.032

Nishida, H., Kajisa, T., Miyazawa, Y., Tabuse, Y., Yoda, T., Takeyama, H., . . . Sakata, T. (2015). Selforiented immobilization of DNA polymerase tagged by titanium-binding peptide motif. Langmuir, 31 (2), 732-740. doi:10.1021/la503094k

Pagel, M., Hassert, R., John, T., Braun, K., Wiessler, M., Abel, B., \& Beck-Sickinger, A. G. (2016). Multifunctional Coating Improves Cell Adhesion on Titanium by using Cooperatively Acting Peptides. Angew Chem Int Ed Engl, 55 (15), 4826-4830. doi:10.1002/anie.201511781

Prince, J. T., McGrath, K. P., DiGirolamo, C. M., \& Kaplan, D. L. (1995). Construction, cloning, and expression of synthetic genes encoding spider dragline silk. Biochemistry, 34 (34), 10879-10885. doi:10.1021/bi00034a022

Sambrook, J., Fritsch, E. F., \& Maniatis, T. (1989). Molecular Cloning: A Laboratory Manual, 2nd Ed. Cold Spring Harbor, NY: Cold Spring Harbor Laboratory.

Sano, K., Ajima, K., Iwahori, K., Yudasaka, M., Iijima, S., Yamashita, I., \& Shiba, K. (2005). Endowing a Ferritin-Like Cage Protein with High Affinity and Selectivity for Certain Inorganic Materials. Small, 1 (8-9), $826-832$.

Sano, K., Sasaki, H., \& Shiba, K. (2005). Specificity and biomineralization activities of Ti-binding peptide-1 (TBP-1).Langmuir, 21 (7), 3090-3095.

Sano, K., \& Shiba, K. (2003). A hexapeptide motif that electrostatically binds to the surface of titanium. $J$ Am Chem Soc, 125 (47), 14234-14235. doi:10.1021/ja038414q

Saotome, T., Hayashi, H., Tanaka, R., Kinugasa, A., Uesugi, S., Tatematsu, K.-i., . . . Asakura, T. (2015). Introduction of VEGF or RGD sequences improves revascularization properties of Bombyx mori silk fibroin produced by transgenic silkworm. Journal of Materials Chemistry B, 3 (35), 7109-7116. doi:10.1039/C5TB00939A

Schneider, J., \& Ciacchi, L. C. (2012). Specific material recognition by small peptides mediated by the interfacial solvent structure. Journal of the American Chemical Society, 134 (4), 2407-2413. doi:10.1021/ja210744g

Schuler, M., Owen, G. R., Hamilton, D. W., de Wild, M., Textor, M., Brunette, D. M., \& Tosatti, S. G. (2006). Biomimetic modification of titanium dental implant model surfaces using the RGDSP-peptide sequence: a cell morphology study. Biomaterials, 27 (21), 4003-4015. doi:10.1016/j.biomaterials.2006.03.009

Scott, J. K., \& Smith, G. P. (1990). Searching for peptide ligands with an epitope library. Science, 249 (4967), 386-390.

Shiba, K. (2010). Natural and artificial peptide motifs: their origins and the application of motifprogramming. Chem Soc Rev, 39 (1), 117-126. doi:10.1039/b719081f 
Skelton, A. A., Liang, T., \& Walsh, T. R. (2009). Interplay of sequence, conformation, and binding at the Peptide-titania interface as mediated by water. ACS Appl Mater Interfaces, 1 (7), 1482-1491. doi:10.1021/am9001666

Strydom, D. J., Haylett, T., \& Stead, R. H. (1977). The amino-terminal sequence of silk fibroin peptide CP - a reinvestigation. Biochem Biophys Res Commun, 79 (3), 932-938. doi:10.1016/0006-291x(77)91200-1

Suzuki, Y., Aoki, A., Nakazawa, Y., Knight, D. P., \& Asakura, T. (2010). Structural Analysis of the Synthetic Peptide (Ala-Gly-Ser-Gly-Ala-Gly)5, a Model for the Crystalline Domain of Bombyx mori Silk Fibroin, Studied with 13C CP/MAS NMR, REDOR, and Statistical Mechanical Calculations. Macromolecules, 43 (22), 9434-9440. doi:10.1021/ma1018878

Suzuki, Y., Shindo, H., \& Asakura, T. (2016). Structure and Dynamic Properties of a Ti-Binding Peptide Bound to TiO2 Nanoparticles As Accessed by (1)H NMR Spectroscopy. J Phys Chem B, 120 (20), 4600-4607. doi:10.1021/acs.jpcb.6b03260

Takei, F., Kikuchi, Y., Kikuchi, A., Mizuno, S., \& Shimura, K. (1987). Further evidence for importance of the subunit combination of silk fibroin in its efficient secretion from the posterior silk gland cells.J Cell Biol, 105 (1), 175-180. doi:10.1083/jcb.105.1.175

Tamura, T., Thibert, C., Royer, C., Kanda, T., Abraham, E., Kamba, M., . . . Couble, P. (2000). Germline transformation of the silkworm Bombyx mori L. using a piggyBac transposon-derived vector. Nat Biotechnol, 18 (1), 81-84. doi:10.1038/71978

Tanaka, K., Kajiyama, N., Ishikura, K., Waga, S., Kikuchi, A., Ohtomo, K., . . Mizuno, S. (1999). Determination of the site of disulfide linkage between heavy and light chains of silk fibroin produced by Bombyx mori. Biochim Biophys Acta, 1432 (1), 92-103. doi:10.1016/s0167-4838(99)00088-6

Tanaka, K., Mori, K., \& Mizuno, S. (1993). Immunological identification of the major disulfide-linked light component of silk fibroin. J Biochem, 114 (1), 1-4. doi:10.1093/oxfordjournals.jbchem.a124122

Teule, F., Miao, Y. G., Sohn, B. H., Kim, Y. S., Hull, J. J., Fraser, M. J., Jr., . . . Jarvis, D. L. (2012). Silkworms transformed with chimeric silkworm/spider silk genes spin composite silk fibers with improved mechanical properties. Proc Natl Acad Sci U S A, 109 (3), 923-928. doi:10.1073/pnas.1109420109

Thurber, A. E., Omenetto, F. G., \& Kaplan, D. L. (2015). In vivo bioresponses to silk proteins. Biomaterials, 71 , 145-157. doi:10.1016/j.biomaterials.2015.08.039

Tsuji, T., Oaki, Y., Yoshinari, M., Kato, T., \& Shiba, K. (2010). Motif-programmed artificial proteins mediated nucleation of octacalcium phosphate on titanium substrates. Chemical communications, 46 (36), 6675-6677. doi:10.1039/c0cc01512a

Velema, J., \& Kaplan, D. (2006). Biopolymer-based biomaterials as scaffolds for tissue engineering. Adv Biochem Eng Biotechnol, 102 , 187-238. doi:10.1007/10_013

Vepari, C., \& Kaplan, D. L. (2007). Silk as a Biomaterial. Prog Polym Sci, 32 (8-9), 991-1007. doi:10.1016/j.progpolymsci.2007.05.013

Vidal, G., Blanchi, T., Mieszawska, A. J., Calabrese, R., Rossi, C., Vigneron, P., . . . Egles, C. (2013). Enhanced cellular adhesion on titanium by silk functionalized with titanium binding and RGD peptides. Acta Biomater, 9 (1), 4935-4943. doi:10.1016/j.actbio.2012.09.003

Wishart, D. S. (2011). Interpreting protein chemical shift data.Prog Nucl Magn Reson Spectrosc, 58 (1-2), 62-87. doi:10.1016/j.pnmrs.2010.07.004

Yanagisawa, S., Zhu, Z., Kobayashi, I., Uchino, K., Tamada, Y., Tamura, T., \& Asakura, T. (2007). Improving cell-adhesive properties of recombinant Bombyx mori silk by incorporation of collagen or fibronectin derived peptides produced by transgenic silkworms.Biomacromolecules, 8 (11), 3487-3492. doi:10.1021/bm700646f 
Yang, M., \& Asakura, T. (2005). Design, expression and solid-state NMR characterization of silk-like materials constructed from sequences of spider silk, Samia cynthia ricini and Bombyx mori silk fibroins. $J$ Biochem, 137 (6), 721-729. doi:10.1093/jb/mvi090

Yang, M., Kawamura, J., Zhu, Z., Yamauchi, K., \& Asakura, T. (2009). Development of silk-like materials based on Bombyx mori and Nephila clavipes dragline silk fibroins. Polymer, 50 (1), 117-124. doi:10.1016/j.polymer.2008.10.008

Yang, M., Muto, T., Knight, D., Collins, A. M., \& Asakura, T. (2008). Synthesis and characterization of silklike materials containing the calcium-binding sequence from calbindin D9k or the shell nacreous matrix protein MSI60. Biomacromolecules, 9 (1), 416-420. doi:10.1021/bm700665m

Yang, M., Tanaka, C., Yamauchi, K., Ohgo, K., Kurokawa, M., \& Asakura, T. (2008). Silklike materials constructed from sequences of Bombyx mori silk fibroin, fibronectin, and elastin. J Biomed Mater Res A, 84 (2), 353-363. doi:10.1002/jbm.a.31348

Yang, M., Yamauchi, K., Kurokawa, M., \& Asakura, T. (2007). Design of silk-like biomaterials inspired by mussel-adhesive protein. Tissue Eng, 13 (12), 2941-2947. doi:10.1089/ten.2006.0448

Yao, J., Ohgo, K., Sugino, R., Kishore, R., \& Asakura, T. (2004). Structural analysis of Bombyx mori silk fibroin peptides with formic acid treatment using high-resolution solid-state 13C NMR spectroscopy.Biomacromolecules, 5 (5), 1763-1769. doi:10.1021/bm049831d

Yoshinari, M., Kato, T., Matsuzaka, K., Hayakawa, T., \& Shiba, K. (2010). Prevention of biofilm formation on titanium surfaces modified with conjugated molecules comprised of antimicrobial and titanium-binding peptides. Biofouling, 26 (1), 103-110. doi:10.1080/08927010903216572

Zhang, F., Zhang, Z., Zhu, X., Kang, E. T., \& Neoh, K. G. (2008). Silk-functionalized titanium surfaces for enhancing osteoblast functions and reducing bacterial adhesion. Biomaterials, 29 (36), 4751-4759. doi:10.1016/j.biomaterials.2008.08.043

Zhou, C. Z., Confalonieri, F., Jacquet, M., Perasso, R., Li, Z. G., \& Janin, J. (2001). Silk fibroin: structural implications of a remarkable amino acid sequence. Proteins, 44 (2), 119-122. doi:10.1002/prot.1078

Zhou, C. Z., Confalonieri, F., Medina, N., Zivanovic, Y., Esnault, C., Yang, T., . . . Li, Z. G. (2000). Fine organization of Bombyx mori fibroin heavy chain gene. Nucleic Acids Res, 28 (12), 2413-2419. doi:10.1093/nar/28.12.2413 
(a)

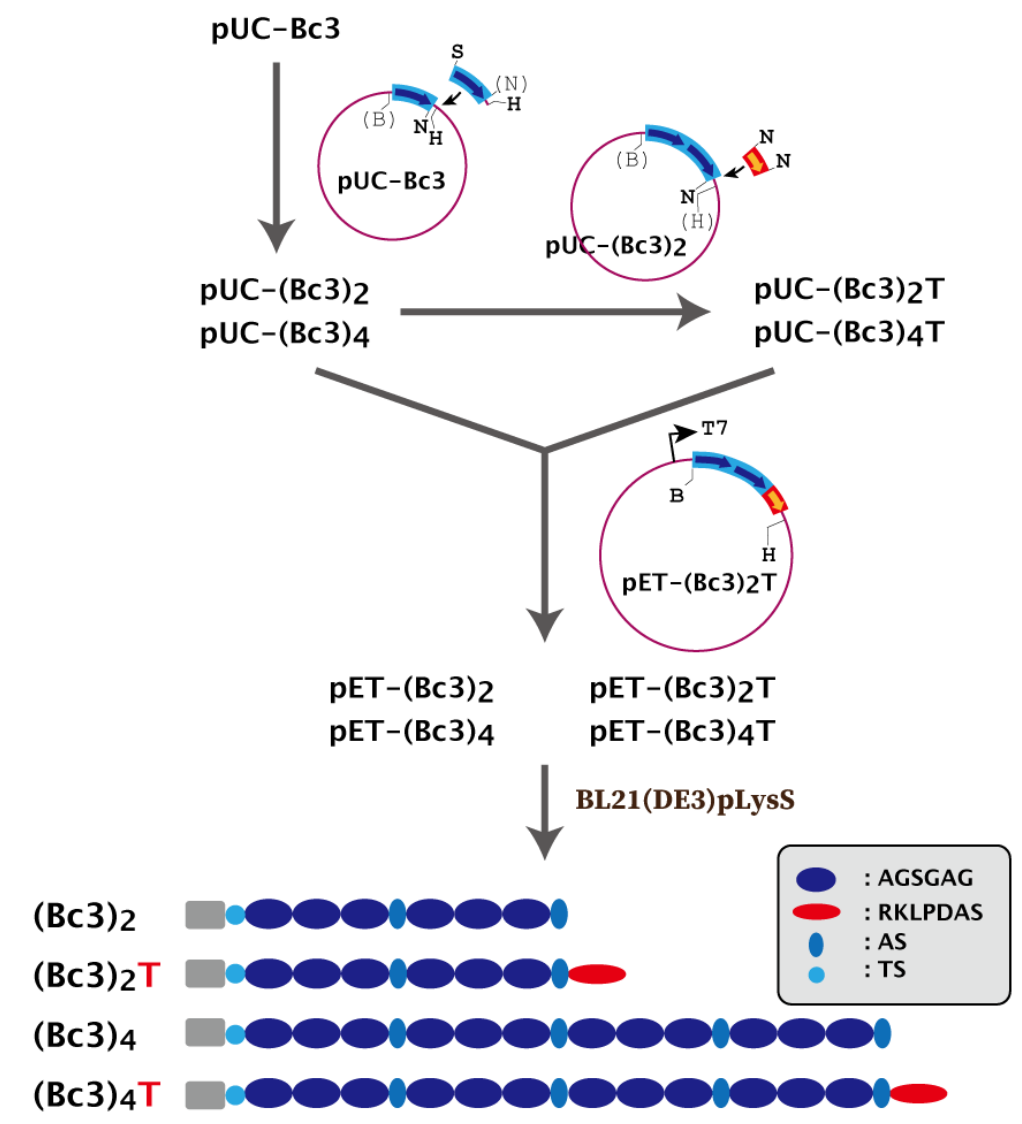

(b)

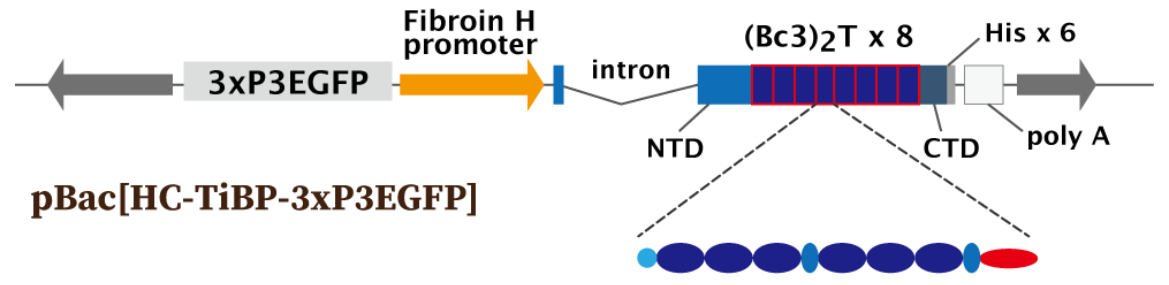

TS[(AGSGAG) $\left.{ }_{3} A S\right]_{2}$ RKLPDA

(c)

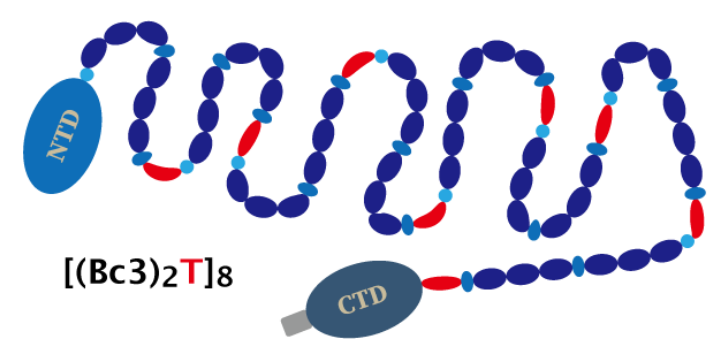


(a)

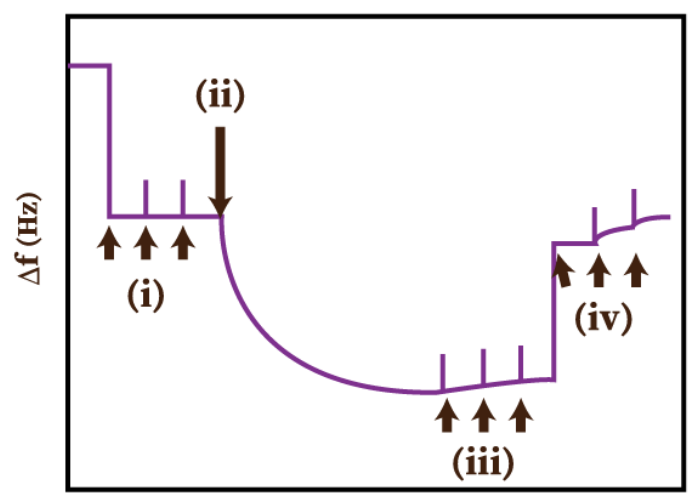

Time

(i) buffer injection $\longrightarrow$ (ii) sample injection

$\longrightarrow$ (iii) buffer wash $\longrightarrow$ (iv) water wash

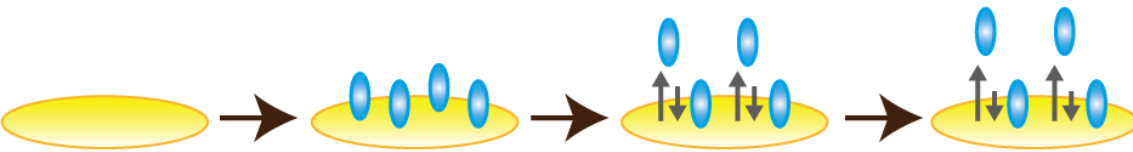

(b)

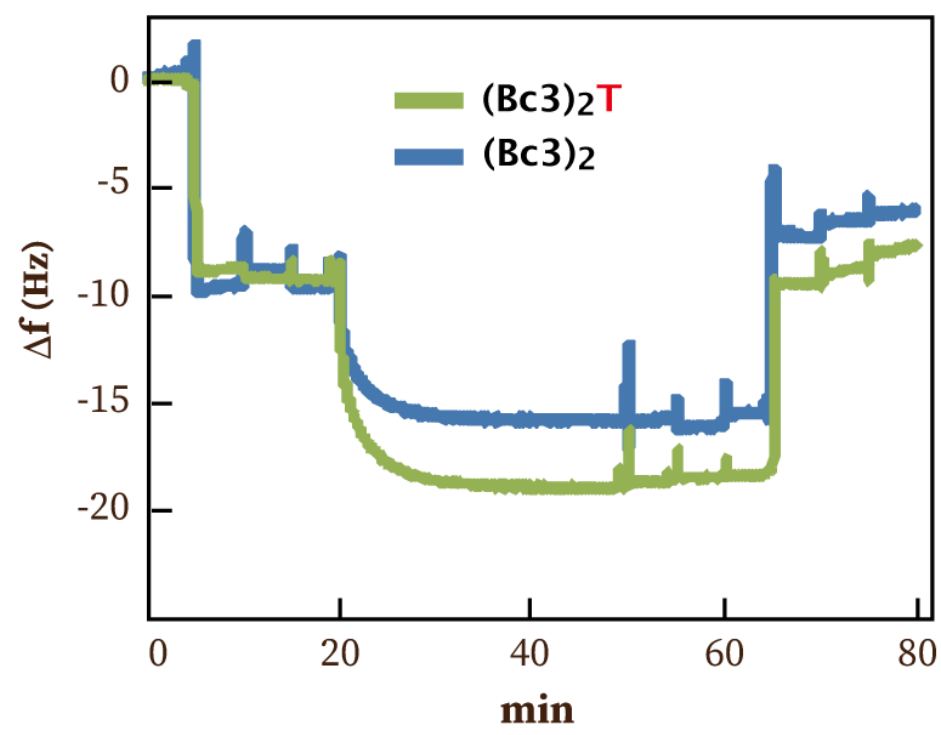

(c)

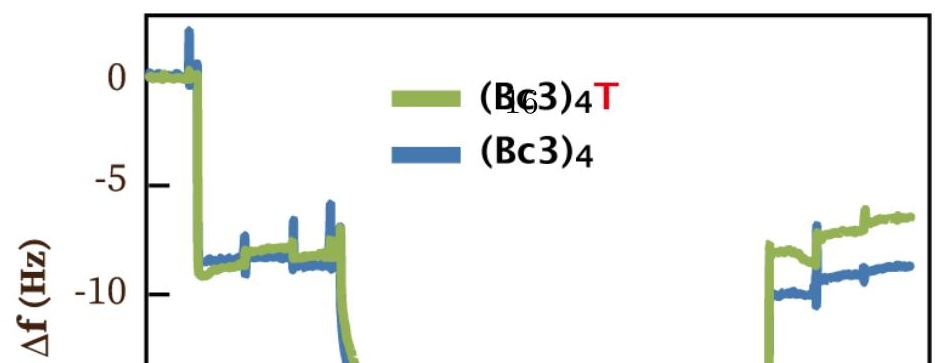


(a)

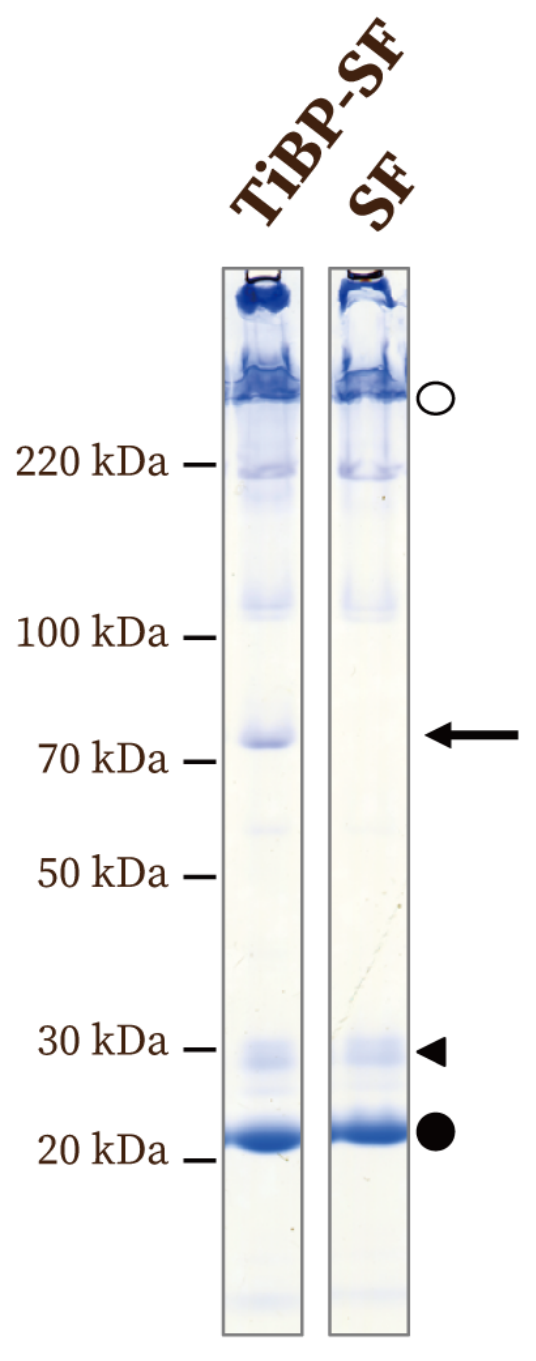

(b)

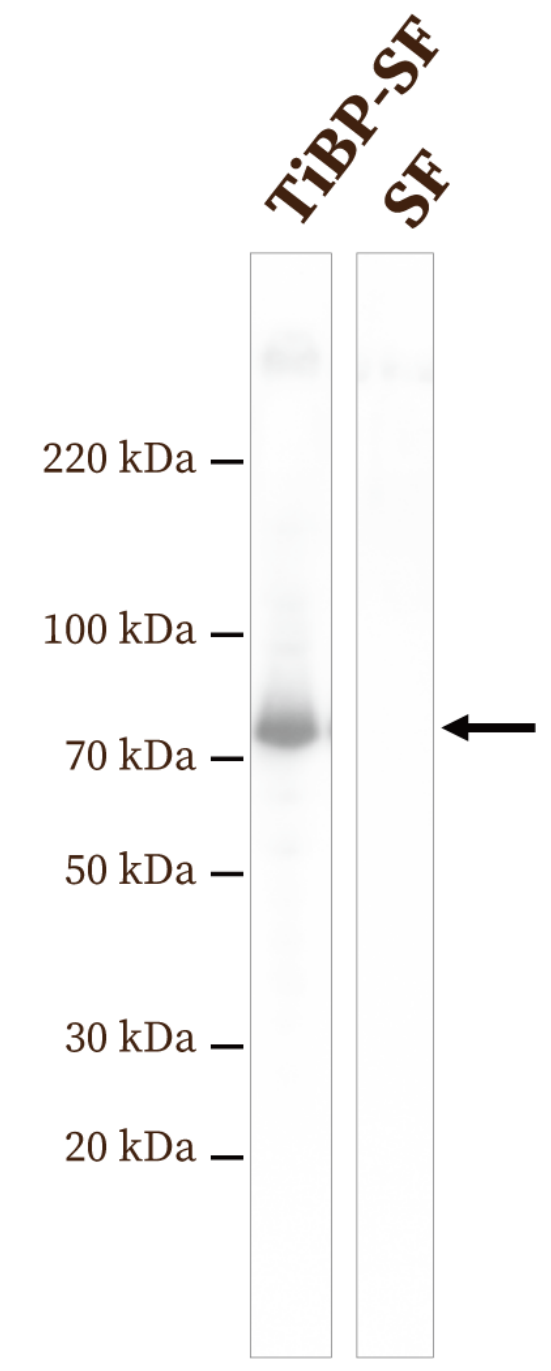


(a)

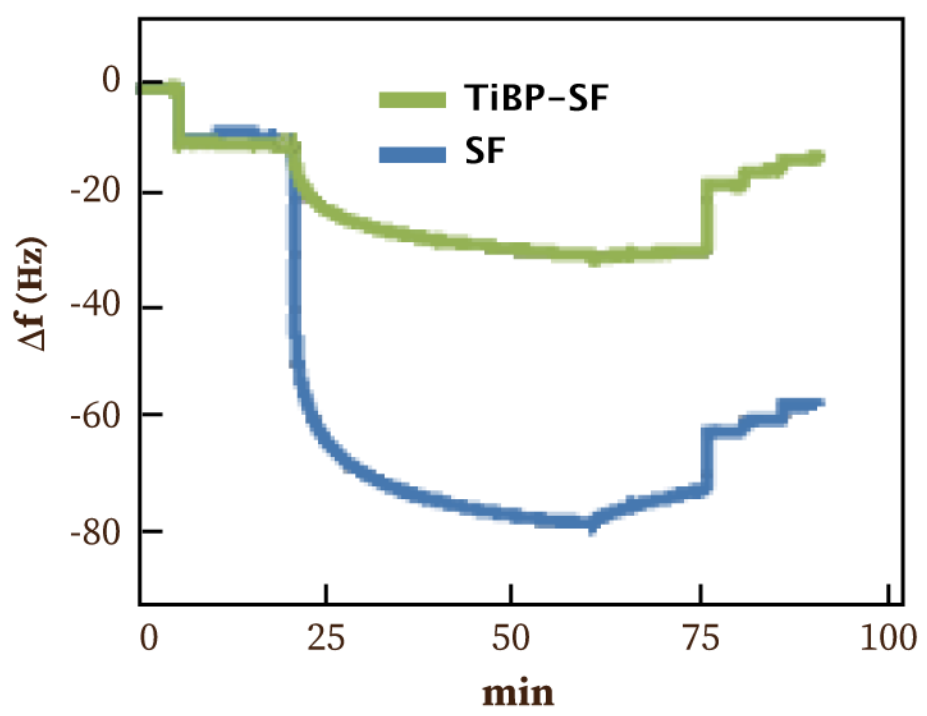

(b)

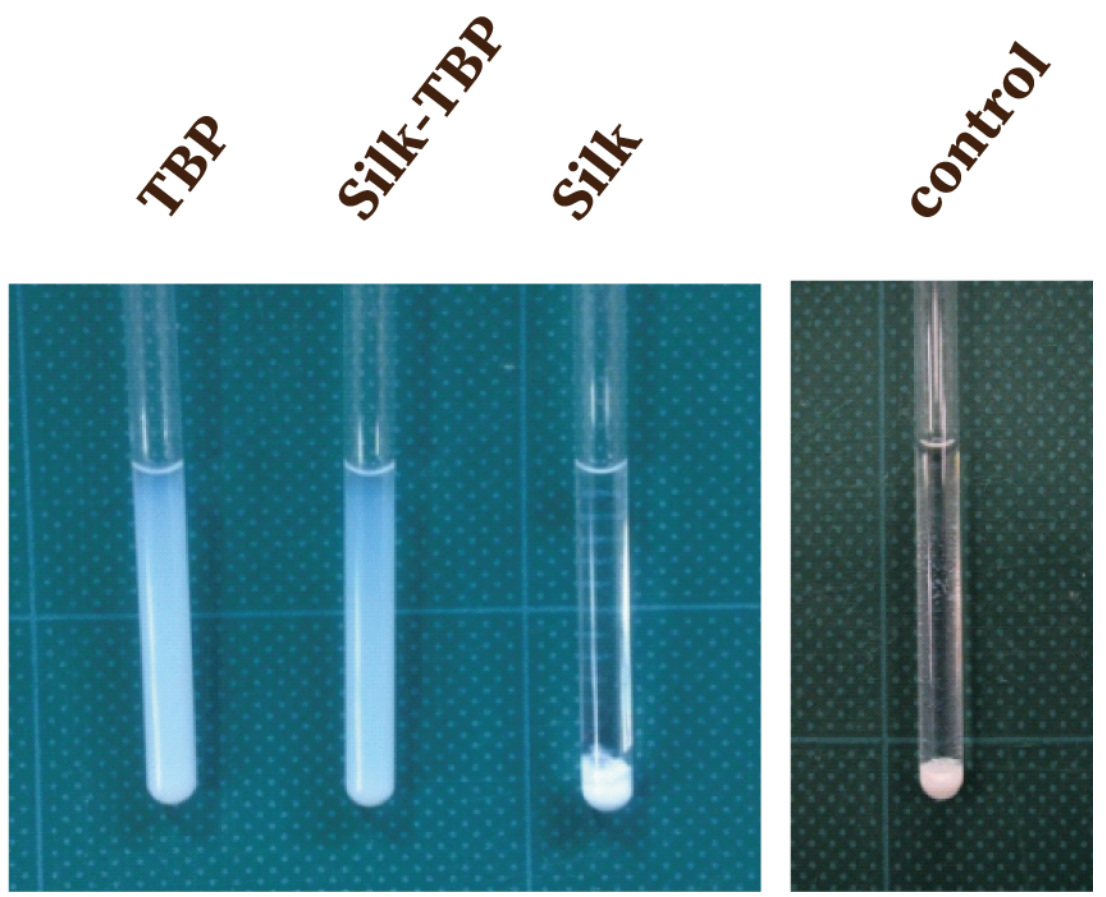


(a)

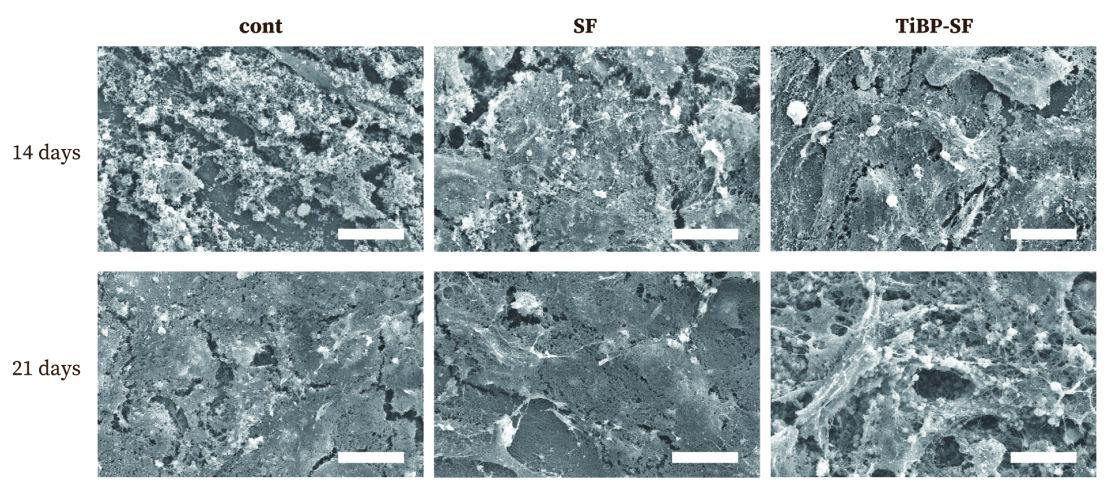

(b)

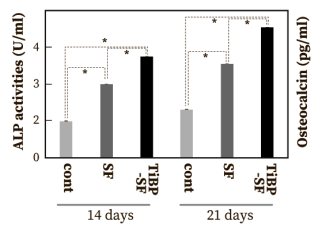

(c)
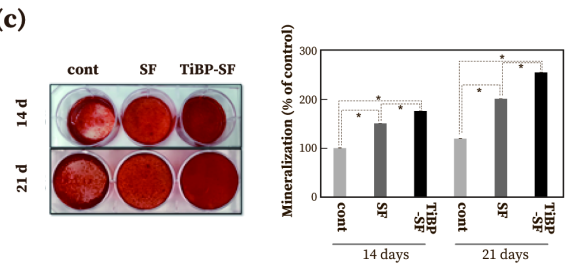

(a)

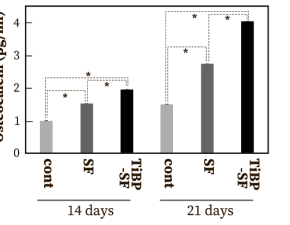

(d)

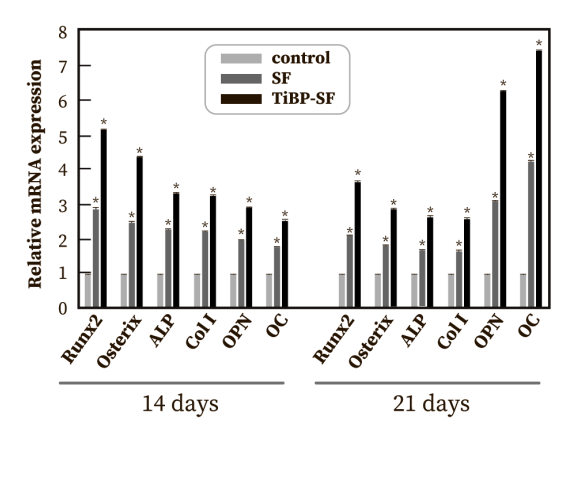

Ala $\mathbf{C}^{\alpha}$

(random coil)

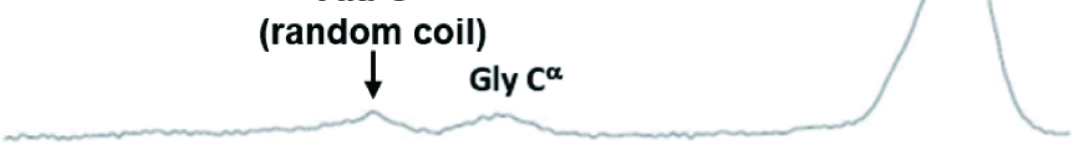

(b)

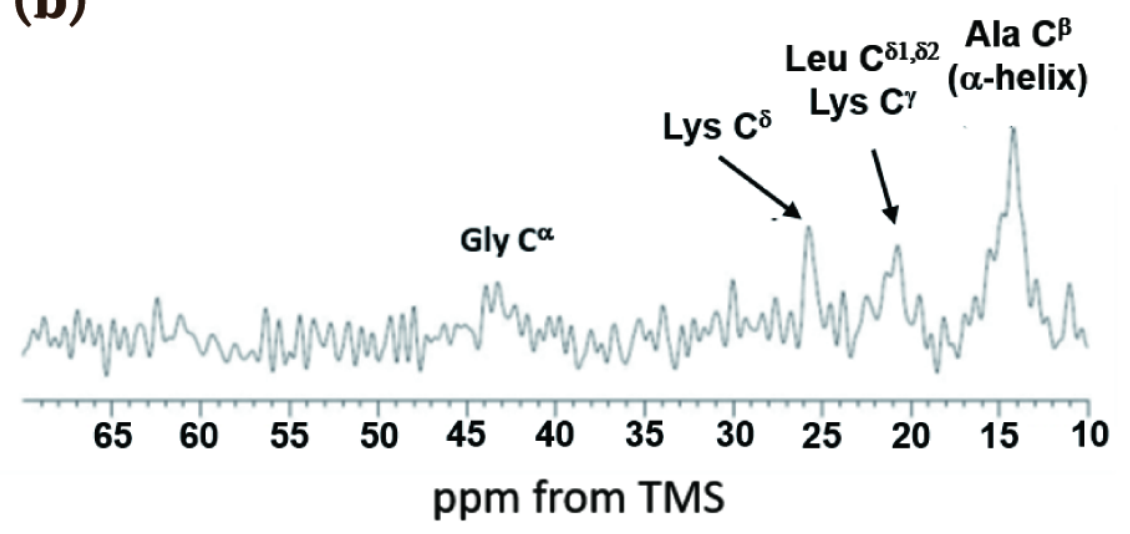




\section{Hosted file}

Table 1.docx available at https://authorea.com/users/354975/articles/478415-biofunctionalized-titanium-surfaces-with-the-modified-silk-fibroin-carrying-titaniumbinding-motif-enhanced-the-ossific-differentiation-of-mc3t3-e1 